\title{
Discussion: An integral composite bridge of high skew
}

\section{B. Bell}

B. Duguid Mott MacDonald Ltd, Manchester, UK

The author notes that it was thought desirable for the bridge to be integral, with no joints in the carriageway or bearings. However, joints have been included and will therefore present a future maintenance liability. Was any consideration given to eliminating joints entirely?

Reinforced soil abutments were used, and the author notes that most of their settlement would occur during their construction. Was this borne out during construction, i.e. did no relative vertical movement occur across the joint after completion?

\section{Author's reply}

Joints in the bridge structure, and all bearings, have been eliminated, in the spirit of integral bridges. Joints in the carriageway have not, as observed by the questioner. Consideration was given to eliminating the carriageway joints as well, perhaps by continuing the bridge deck longitudinally (integral with the run-on/apron slabs), tapering the slabs for flexibility and directing them downwards under the road construction. The resulting length of the longer diagonal of each carriageway's slab would have been some $80 \mathrm{~m}$. The cyclic movement of the buried slab at the free end was considered excessive. Since the original, three span, scheme had these apron slabs and their asphaltic plugs, which were acceptable to the client, it was considered satisfactory to retain these features while halving the number of asphaltic plugs.

The River Nanny bridge was opened on 9 June 2003, immediately on its completion, at the same time as the River Boyne bridge on the same stretch of motorway. At the time of writing, some eight months later, there was no evidence of relative vertical movement across the joints. 